\title{
Når gamle mennesker vaelger livet fra
}

\author{
Ved Annette Erlangsen
}

\begin{abstract}
Selumord forekommer i alle aldersgrupper, dog er det de aeldste som hyppigst begår selumord $i$ Danmark som i flere andre land. Denne artikel beskriver hvilke omstoendigheder som gør at aeldre oftere enn de yngre synes at livet ikke loengere er voerd at leve. Baseret på seneste forskningsresultater karakteriseres risikogrupper for selvmord blandt celdre personer samt dokumenteret forebyggelse. Ligeledes sammenlignes norske og danske selumordsrater.
\end{abstract}

\section{Flere aldre mennesker}

Over de seneste årtier er den gennemsnitlige levetid steget markant i de fleste vesteuropæiske lande. Vi lever længere end tidligere, og det er nogle store generationer som står overfor at pensioneres i de kommende årtier (Jeune, 2002).

Antallet af ældre vil således også stige i fremtiden. Forskningen viser at nutidens ældre menneskers sidste livsår er præget af færre kroniske sygdomme og funktionsproblemer end tidligere generationers (Freedman et al., 2002). Livskvaliteten for ældre mennesker burde være højere nu om dage end for blot 20-30 år siden, specielt for de ældste ældre over 80 år.

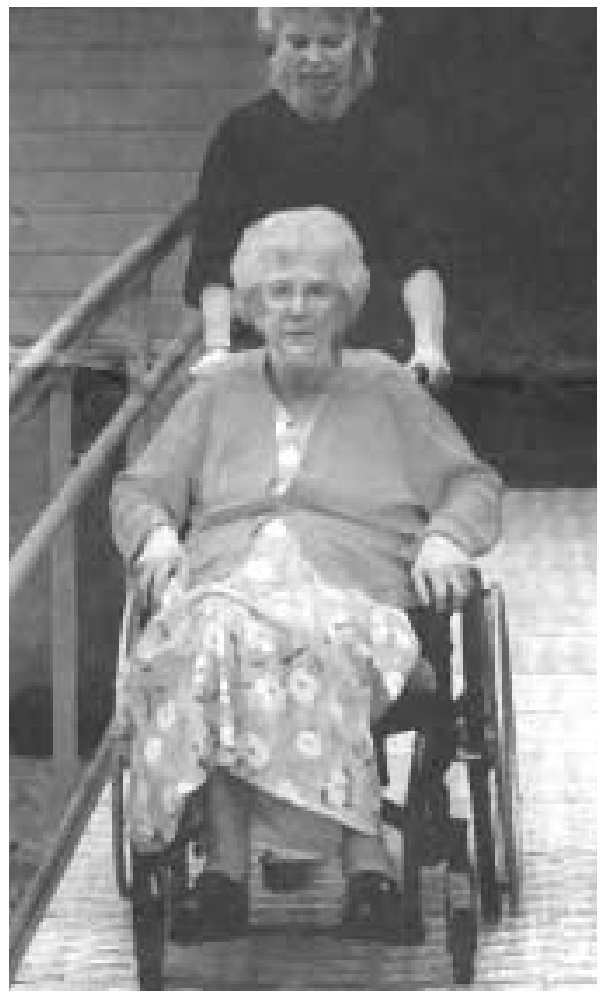

Desværre har disse forhold ikke afspejlet sig i de ældres selvmordsrater i Danmark. Mens selvmordsraten for hele befolkningen har været faldende over de seneste årtier, har raten for de ældre 80 år og derover ikke ændret sig signifikant (Erlangsen et al., 2003).

\section{At blive gammel}

Alderdommen kan i mange tilfælde indeholde omskiftninger og tab som kræver tilvænning. Man går på pension, hvilket kan være en svær omstilling for mænd der har været vant til rollen som familiefors $\varnothing$ rger. Kroppen er mindre modstandsdygtig og man kan klare færre fysisk hårde opgaver end tidligere.

Med stigende alder får ældre i st $\varnothing$ rre grad brug for hjælp til forskellige gøremål (Jeune, 2002). Det kan være svært at acceptere at man er afhængig af hjælp fra andre til ting som man tidligere kunne gøre selv. Det kan handle om at passe sin egen have, ikke længere være i stand til at gå på jagt, men også om personlig pleje, så som at tage bad eller gå på toilettet (Anneberg, 2004). Kroppens funktioner svækkes også med stigende alder. Man kan ikke høre så godt, behøver briller, ens smags- og lugtesans ændre sig eller forsvinder delvist, man får protese.

Dertil kommer $\varnothing$ mtålelige emner som inkontinens.

\section{Selvmord hos aeldre}

Som nævnt ovenfor er selvmordsraten blandt ældre mennesker betydeligt højere end hos yngre aldersgrupper. Dette gælder især for mænd. I 2002 var selvmordsraten for mænd over 75 år i Norge på 28 per 100.000 , mens kvinder i den samme aldersgruppe havde en selvmordsrate på 4 per 100.000 (Figur 1). For mænd er dette den højeste selvmordsrate af alle aldersgrupper, mens norske kvinder i aldersgruppen 55-64 havde den højeste rate. I Danmark havde i 2000 de ældre over 75 år den højeste selvmordsrate af alle aldersgruppe for begge $k \varnothing n$. Som det ses i figur 2, var den 52 og 18 per 100.000 for henholdsvis mænd og kvinder.

Modsat mange andre lande, har de ældre i Norge historisk set ikke været den aldersgruppe med den højeste selvmordsrate (De Leo et al., 1997; Sverre, 1991).
I Danmark havde de ældre allerede for over 100 år siden den højeste selvmordsrate (Kayser, 1846; Pæregaard, 1980).

Figur 1. Selvmordsrate per 100.000 for norske maend og kvinder efter aldersgruppe, 2002.

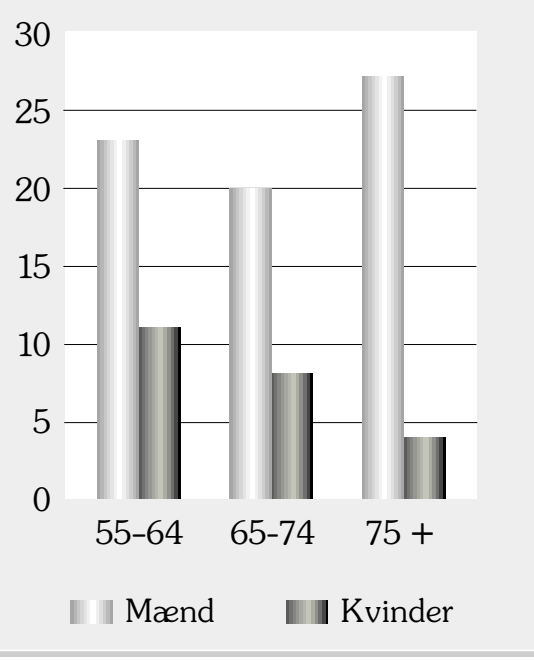

D atakilde: Statistisk sentralbyrå

Figur 2. Selvmordsrate per 100.000 for danske maend og kvinder efter aldersgruppe, 2000.

60

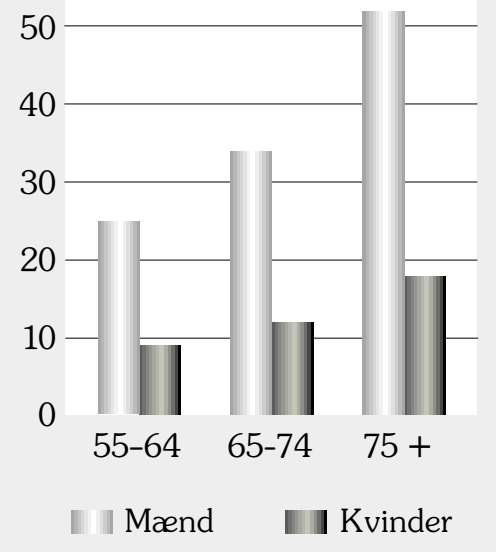

D atakilde: Sundhedsstyrelsen 


\section{Sammenligning af selvmords- rater fra forskellige lande}

$\mathrm{N}$ år man sammenligner selvmordstal fra forskellige lande er det vigtigt, at tage højde for at registreringen af selvmord kan variere fra land til land. Definitionen for hvad der er et selvmord i et land, er ikke nødvendigvis den samme som i andre lande. Der kan være sociale forskelle på forståelsen af hvad et selvmord er, ligesom der kan være kulturelt begrundede motiver for at 'skjule' et selvmord som en anden dødsårsag ( selvmord er f.eks. ifølge den katolske religion en synd som går udover døden). Dertil kommer at sikkerheden hvormed en dødsårsag konstateres, afhænger af hvor mange dødsfald som bliver obduceret. 0 bduktionsraten varierer også mellem forskellige lande.

Den lave obduktionsrate for dødsfald blandt ældre medfører sandsynligvis at pålideligheden af dødsårsagsregistreringen for denne aldersgruppe er påvirket. (Ekeberg, et al 1985). A f samme årsag må det forventes at antallet af egentlige selvmord blandt ældre er højere end det som gengives i selvmordsstatistikerne.

\section{Selvmord i Danmark og Norge}

Det er vigtigt at have sig de ovennævnte forhold for øje når man sammenligner selvmordsrater på tværs af landegrænser, også sel vom N orge og Danmark har mange fælles træk.

Tidligere studier vurderer at forskellen mellem nordmændenes og danskernes selvmordshyppighed reflekterer egentlige forskelle, som ikke udelukkende kan forklares med forskellige registreringspraksis (H essø, 1987; K olmos \& Bach, 1987).

U nni Bille-Brahe (1987) har fremhævet at den sociale integration er mere udviklet i N orge end Danmark, og at dette kan forklare en del af forskellen i de to landes selvmordsrater. Integrationsniveauet beskriver den enkelte personstilhørsforhold til samfundet. Integrationsforhol det virker $i$ begge retninger, dvs. at den enkelte medborger føler, at samfundet er der når man har problemer og behøver hjælp, men også at medlemmer af samfundet føler, at de udgør en vigtig del af samfundet og at 'fæll lesskabet' har brug for dem.

Der findes sandsynligvis andre velegnede forklaringsmodeller for forskellen mellem nordmændenes og danskernes selvmordstendens.

\section{Beslutsomme selvmordsmetoder}

EE Idre som begår selvmord er meget besluttede, og deres handlinger mislykkes i færre tilfælde end hos yngre personer (De Leo et al., 2001). De benytter meget drastiske metoder til at afslutte livet på. Studier af norske ældre som overlevede et sel vmordsforsøg viser at de undersøgte havde en høj selvmordsintention (Kjølseth \& Ekeberg, 1997). A rsagerne for deres forsøg var hos mange af personerne personlige tab og nedsat funktionsevne.

Det er determinerede metoder som de ældre benytter når de vil sætte livet en ende. En stor andel af de ældres selvmord udføres ved hængning, specielt blandt mænd men også blandt æl dre kvinder. 0 mkring $60 \%$ af de danske ældre mænd på over 80 år som tog deres liv i perioden 1994-1998 gjorde dette ved at hænge sig, mens omkring 1 ud af 3 kvinder fyldt $80+$ der døde af selvmord benyttede samme metode. H os kvinder er overdosis stadig den hyppigst anvendte selvmordsmetode (Erlangsen et al., 2003). I N orge begås en forholdsvisstor andel af selvmord blandt ældre mænd ved hængning, mens de fleste ældre kvinder begår selvmord ved overdosis af piller eller drukning (Statistisk sentral byrå, 2004).

\section{Agteskabelig status og selvmord}

$M$ an taler generelt om at ægteskab har en beskyttende virkning mod selvmord (Retterstøl, 1993). Dette gæl der også for de ældre aldersgrupper, typisk har gifte ældre en lavere selvmordsrate end ugifte, fraskilte og efterladte. Dog i takt med stigende alder, steg også sel vmordsraten for ældre gifte i Danmark (Erlangsen et al., 2003). M ens der er stor forskel på selvmordsraten for gifte og efterladte mænd i Danmark, enkemænd har en to-tre gange højere selvmordsrate end gifte mænd, er raten stort set ens for gifte og efterladte kvinder. Dette gæl der særligt for de æl dre over 80 år (ibid).

\section{Belastende og stressfulde haendelser}

A Iderdommen kan være præget af personlige tab, som når ens partner eller andre nærtstående personer dør. Det at opleve at ens ægtefælle dør, kan i nogle tilfælde medføre depression. Studier viser at æl dre mænds risiko for at begå selvmord er 6-8 gange højere i det første år efter partners død end hos gifte ældre. For ældre kvinder stiger risikoen 5-8 gange i forhold til gifte kvinder (Erlangsen et al., 2004). A ndre omstillinger som at skulle flytte på plejehjem eller pensioneres - eller forventningen herom - er muligvis også forbundet med en højere selvmordsrisiko.

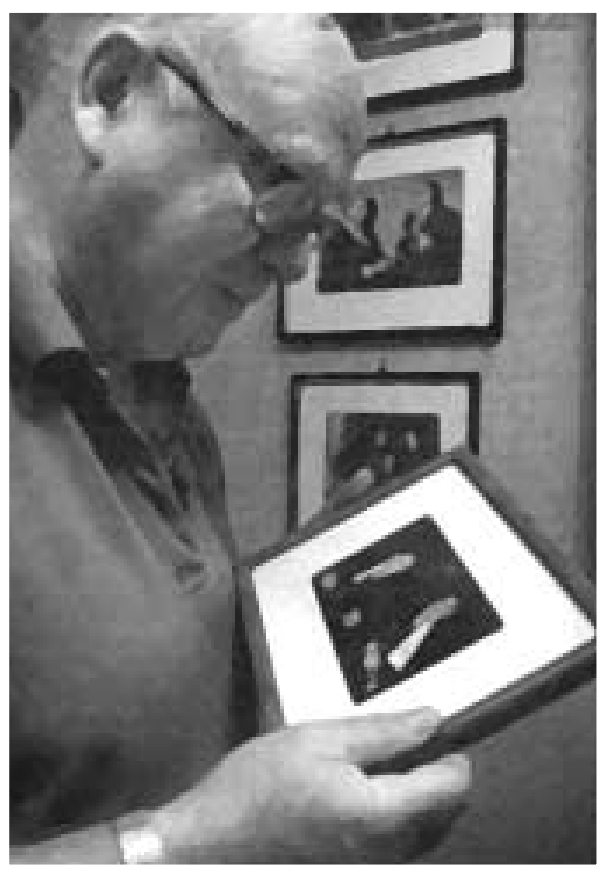

Depression og fysisk sygdom

Selvom depression ikke nødvendigvis har en højere prævalens hos ældre personer end yngre personer, forekommer der flere selvmord blandt æl dre hvor personen havde udvist depressive symptomer end blandt yngre aldersgrupper (Zarit \& Zarit, 1998; C onwell et al., 1996). En forklaring kan være at en større andel ældre med depressioner ikke bliver identificeret (Sørensen, 2001). Det kan til en vis grad skyldes den fejlagtige antagelse at der at normalt at være lidt trist, hvis man er ældre. I mange tilfælde har den ældre person som udvikler en affektiv sygdom ikke tidligere haft depressive symptomer, det er således tale om en første episode af sygdommen (C onwell et al., 1991), som er relativt nemt at behandle, hvis de bliver identificeret.

Personer med affektive sygdomme har en høj risiko for at begå selvmord (Erlangsen, 2004). Det vurderes at størstedel en af de ældre som begår selvmord har haft 
en depression i tiden op til selvmordet (C onwell et al., 1996; W aern et al., 2002b). Svær fysisk sygdom medfører også en højere risiko for at ældre begår selvmord (C onwell et al., 1996; Erlangsen, 2004; W aern, et al., 2002a).

\section{Selvmord kan forebygges}

Der findes kun få forebyggende initiativer rettet mod selvmord hos ældre til trods for at nogle projekter har kunnet dokumentere en virksom intervention. Et eksempel på et vellykket interventionsprogram blev udført i Padua, Italien, hvor en gruppe af ældre personer med en højere selvmordsrisiko blev inviteret til at deltage i et forskningsprojekt (De Leo et al., 2002). Deltagerne fik installeret et alarmsystem i deres hjem, således at de til enhver tid kunne kontakte en alarmcentral, hvis de behøvede hjælp. H ver uge blev de kontaktet telefonisk, hvor der bl.a. blev spurgt til hvordan de havde det og om der var noget de behøvede hjælp med. Efter 9 år blev programmet evalueret og man fandt at der havde forekommet færre selvmord blandt deltagerne end blandt jævnaldrende i en nabokommune. Selvom deltagerne var i en risikogruppe begik de færre selvmord end hos personer med en normal (lavere) risiko.

D et er overraskende hvor få initiativer der iværksættes til forebyggelse af ældres selvmord. I sær når man tager deres høje selvmordsrate i betragtning. Ligger der en overordnet holdning bag - at det ikke er så slemt når et ældre menneske begår selvmord - vedkommen de vil jo alligevel dø inden så længe? I et velfærdssamfund som disse ældre i stor grad har bidraget til, har vi vel råd til at sørge for at vore ældre medborgere har et leveværdigt liv.

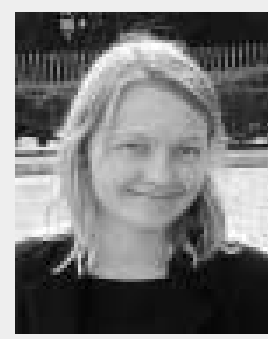

A nnette Erlangsen har en uddannelse $\mathrm{i}$ sociologi, hun forsvarede ph.d.-afhandlingen Disparities in suicide among the old and oldest old in Denmark ved Epidemiologi, Syddansk U niversitet i 2004. Efter at have afsluttet hendes afhandling blev hun ansat som forsker ved $C$ enter for Registerforskning, $A$ arhus U niversitet, Danmark. $\mathrm{H}$ un arbejder på nuværen de tidspunkt på et dansk-amerikansk forskningsprojekt om determinanter for selvmord blandt de ældre i D anmark.

\section{Referencer}

A nneberg, I. (2004). I ridser mine nerver... I Tellervo, J. (red.). Selvmord blandt gamle mennesker - myter, viden og forebyggelse. København: N yt N ordisk Forlag, s. 85-90.

Bille-Brahe, U. (1987). Suicide and social integration. A pilot study of the integration levels in $N$ orway and D enmark. A cta Psychiatrica Scandinavica Supplementum 76, 45-62.

Conwell, Y., OIsen, K., Caine, E.D., \& Flannery, C. (1991). Suicide in later life: psychological autopsy findings. International Psychogeriatrics 3, 59-66.

Conwell, Y., et al. (1996). R elationships of age and axis I diagnoses in victims of completed suicide: a psychological autopsy study. A merican Journal of Psychiatry 153, 1001-8.

De Leo, D., Buono, M.D., \& Dwyer, J. (2002). Suicide among the elderly: the long-term impact of a telephone support and assessment intervention in northern Italy. B ritish Journal of Psychiatry 181, 226-9.

De Leo, D., Conforti, D., \& Carollo, G. (1997). A Century of Suicide in Italy: A C omparison between the O Id and the Young. Suicide and LifeThreatening Behavior 27, 239-49.

De Leo, D., et al. (2001). A ttempted and completed suicide in older subjects: results from the W $\mathrm{H} \mathrm{O} /$ EU RO Multicentre study of suicidal behaviour. International Journal of G eriatric Psychiatry 16, 300-10

Ekeberg, Ø., Jacobsen, D., \& Enger, E. (1985). Selvmordsstatistikkens pálitelighet i $\mathbf{N}$ orge. Tidsskrift for D en norske laegeforening 105, 123-7.

Erlangsen, A . (2004). D isparities in suicide among the old and oldest old in D enmark. Ph.d.-afhandling. $O$ dense: U niversity of Southern Denmark.

Erlangsen, A ., Bille-Brahe, U ., \& Jeune, B. (2003). $D$ ifferences in suicide between the old and the oldest old. Journal of G erontology: Social Sciences 58B, 314-22.

Erlangsen, A ., J eune, B., Bille-Brahe, U ., \& Vaupel, J.W. (2004). L oss of partner and suicide risks among oldest old: a population-based register study. A ge and A geing 33, 378-83.

Freedman, V.A ., M artin, L.G ., \& Schoeni, R.F. (2002). R ecent trends in disability and functioning among older adults in the $U$ nited States. A systematic review. Journal of the A merical M edical A ssociation 288, 3137-46.

H essø, R. (1987). Scandinavian routines and practices in the registration of suicide. A cta Psychiatrica Scandinavica Supplementum 76, 17-21. Jeune, B. (2002). Længe leve!? 0 m udforskningen af det lange liv. København: Fremad.

Kayser, C,I. (1846). 0 m selvmord i kongeriget $D$ anmark. Et bidrag til dette lands moralske stististik. København: Jens H ostrup Schultz.

Kjølseth, I., \& Ekeberg, Ø. (1997). Selvmordsforsøk hos eldre. Tidsskrift for Den norske laegeforening 117, 3988-91.

Kolmos, L., \& Bach, E. (1987). Sources of error in registering suicide. A cta Psychiatrica Scandinavica Suppl ementum 76, 22-43.

\section{International forskergruppe "Aldre og Selvmord"}

I forbindelse med det 10. European Symposium on Suicide and Suicidal Behaviour i 2004 i København blev der afholdt et møde for forskere, praktikere og andre interesserede i forebyggelse af ældres selvmord. H er blev det besluttet at lave en international forskergruppe $\mathbb{E}$ Idre og Selvmord. G ruppen består af adskillige internationale fors kere som er aktive indenfor dette område. Formålet med gruppen er at fremme udvekslingen af forskningsbaseret viden bl.a. ved at planlægge sessions om æl dre og selvmord ved fremtidige selvmordskonferencer. Derudover kan gruppen fungere som et forum for internationale samarbejdsprojekter. Ved det kommen de årsmøde for A merican A ssociation of Suicidology i Colorado, april i år planlægges en dobbelt plenumsession: Suicide in older adults: risk and prevention. Ligel edes forventes det at der vil blive arrangeret en session ved 23. International A ssociation for Suicide Preventions konference i Durban i september.

Interesserede kan blive optaget på gruppens mailing liste ved at kontakte A nnette Erlangsen, aer@ncrr.dk

Pærregaard, G . (1980). Suicide in D enmark. Suicide and Life-T hreatening Behavior 10, 150-6. RetterstøI, N . (1993). Suicide: a E uropean perspective. C ambridge: C ambridge U niversity Press.

Statistisk sentral byrå (2004). ICD-10 D ødsårsak etter detaljert internasjonal liste.

http://www.ssb.no/emner/03/01/10/dodsarsak/kapxx-v01-y89.html (1.3.05)

Seksjon for selvmordsforskning og -forebygging, U niversitetet i 0 slo.(2004). Selvmord etter aldersgrupper og kjønn.

http://www.med.uio.no/ipsy/ssff/ statistikk/ selvmordetteral dersgrupperogkjonn.pdf (1.3.05)

Sundhedsstyrel sen (2004). D ødsårsagsregistrert 2000. København: Sundhedsstyrelsen.

Sverre, J.M. (1991). Trends in suicide mortality among the elderly in N orway, 1966-1986. Epidemiology 2, 252-6.

Sørensen, L.U . (2001). Psychiatric morbidity and the use of psychotropics in D anish nursing homes. Faculty of $\mathrm{H}$ ealth Sciences, $\mathrm{A}$ arhus: $U$ niversity of A arhus.

W aern, M., et al. (2002a). Burden of illness and suicide in elderly people: $C$ ase-control study. British M edical Journal 324, 1355-9.

W aern, M ., et al. (2002b). Mental disorder in elderly suicides: A case-control study. A merican Journal of Psychiatry 159, 450-5.

Zarit, S.H ., \& Zarit, J.M . (1998). M ental disorders in older adults. $N$ ew York: Guildford Press. 